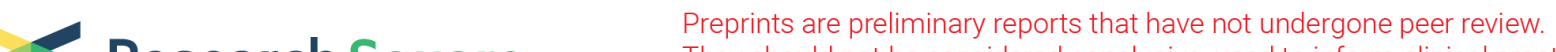 $\begin{array}{ll}\text { Research Square } & \text { They should not be considered conclusive, used to inform clinical practice, } \\ \text { or referenced by the media as validated information. }\end{array}$
}

\section{A Lateral Opening Injection Tool Used In Percutaneous Vertebroplasty To Treat Asymptomatic Osteoporotic Vertebral Burst Fractures: A Retrospective Study In 66 Cases}

\section{Xin Sun}

Shanghai JiaoTong University School of Medicine

Jia Wang

Shanghai JiaoTong University School of Medicine

Xingzhen Liu

Shanghai JiaoTong University School of Medicine

Hairong Tao

Shanghai JiaoTong University School of Medicine

Tong Zhu

Shanghai JiaoTong University School of Medicine

\section{Xiang Wang}

Shanghai JiaoTong University School of Medicine

\section{Kangping Shen}

Shanghai JiaoTong University School of Medicine

Wenjie Jin ( $\square$ surgeonjin@126.com )

Shanghai JiaoTong University School of Medicine

\section{Research Article}

Keywords: osteoporotic vertebral burst fractures, PVP, lateral opening injection tool, bone cement, fracture healing

Posted Date: October 21st, 2021

DOl: https://doi.org/10.21203/rs.3.rs-987798/v1

License: (c) (i) This work is licensed under a Creative Commons Attribution 4.0 International License. Read Full License 


\section{Abstract}

Background: This study aimed to assess the results of percutaneous vertebroplasty (PVP) with a lateral opening injection tool for treating asymptomatic osteoporotic vertebral burst fractures (OVBFs) patients.

Methods: 66 patients diagnosed with acute asymptomatic OVBFs with a spinal canal occupational ratio under $20 \%$ were treated with bilateral PVP using a lateral opening injection tool in our study. The related clinical outcomes and images were assessed, including Visual Analogue Scale (VAS), vertebral height $(\mathrm{VH})$ ratio (=fractured $\mathrm{VH} /$ adjacent nonfractured $\mathrm{VH}$ ), the bone union of the fractured vertebral posterior wall, bone cement distribution, and complications.

Results: The VAS scores were $3.80 \pm 0.40$ at postoperative one day and $0.59 \pm 0.41$ at last follow-up, significantly lower than $8.37 \pm 0.49$ at pre-operation $(P<0.05)$. The vertical distribution of bone cement in 60 cases contacted the upper and lower endplates of fractured vertebras. There was no leakage of bone cement in the spinal canal or displacement of posterior wall fracture to the spinal canal in all cases. There was asymptomatic cement leakage in 7 cases. The mean anterior, middle and posterior vertebral height ratios were significantly increased after PVP compared with preoperative values in all patients $(P<0.05)$. At 6 months follow-up, there was no significant height loss of the vertebral body. Three months postoperatively, the posterior wall of fractured vertebral bodies was healed in all cases according to CT images.

Conclusions: PVP using a lateral opening injection tool was effective and safe for treating asymptomatic OVBF patients.

\section{Introduction}

Osteoporotic vertebral compression fractures (OVCFs) are prevalent in older people, and an estimated 1.7 million new OVCFs occur every year in Europe and the United States [1]. In terms of the different types of OVCFs, there are many OVCF patients with asymptomatic posterior vertebral wall disruption and (or) spinal canal compromise [2-6]. According to the Denis classification, this fracture type involves two columns (anterior and middle) of injury and should be classified as vertebral burst fractures, called osteoporotic vertebral burst fractures (OVBFs) [2-8]. OVBFs can cause persistent deep back pain, impaired gait, and progressive kyphosis, and there is a high risk of nerve compression caused by inappropriate treatments, leading to further nerve dysfunction and even death [9].

Until now, the adequate management of OVBFs has been controversial [10-12]. Surgical pedicle internal fixation treatments have been used in previous literature $[12,13]$. However, many elderly individuals have contraindications or a high risk of accidents during the perioperative period after undergoing general anesthesia and surgery for their poor basic physical condition $[12,13]$. Conservative treatment can also be used as an alternative treatment $[11,14]$. However, conventional treatment usually requires a more extended period of bed rest; as a result, the risk of bed-ridden complications is high in older patients [14]. Additionally, conservative treatment may be highly troublesome due to poor patient compliance and nerve 
injury due to fracture fragment displacement. Regardless of the kinds of treatment undertaken, the incidence of fracture nonunion is still high in older patients [15].

Percutaneous vertebroplasty (PVP) and percutaneous kyphoplasty (PKP), two minimally invasive procedures performed with the radiographically guided injection of polymethyl methacrylate (PMMA) bone cement directly into the vertebral bodies to restore the stability of fractured vertebral bodies and reduce pain, are widely applied for the treatment of OVCFs and easily accepted by elderly patients [16]. Although many surgeons have attempted to use PVP or PKP to treat OVBFs and have achieved satisfactory results, these methods have some complications $[2-5,10,17,18]$. The most critical issue was that bone cement might leak into the spinal canal through the fractured posterior wall or push the burst fracture fragments backward, ultimately causing nerve compression [10]. But how to effectively solve this problem was rarely reported in previous papers. In addition, because the posterior wall of the vertebral body is damaged in burst fracture, so the stability of the middle column of the spine decreases $[7,8]$. How to guarantee the stability of the vertebras with burst fracture after PVP or PKP treatment has not been confirmed.

In clinical work, we found that a lateral opening injection tool could make the bone cement flow from the lateral opening hole. During the operation, the operators could control the flow of bone cement by rotating the punctured tube and adjusting the direction of the lateral opening. Using this injection tool, surgeons can well control the distribution of bone cement during surgery, further reducing the risk of cement leakage and displacement of the burst fracture fragments. Therefore, we attempted to use PVP treatment with a lateral opening injection tool to treat some asymptomatic OVBF patients and reviewed the results of the cases in this study.

\section{Materials And Methods}

\section{Study design and patients}

This is a retrospective case series study. 66 patients diagnosed with single-segment acute OVBFs from T10-L5 with a spinal canal occupational ratio under 20\% were treated with PVP in our spinal operative group between Mar 2016 and Mar 2020. Basic data were recorded in all patients, including age, sex, fracture cause, T-score and spinal canal occupational ratio. The spinal canal occupational ratio was assessed via computed tomography (CT) of the spine using the following equation:

\section{$[1-\mathrm{A} /(\mathrm{B}+\mathrm{C}) / 2] * 100$}

where $A$ is the diameter of the spinal canal at the fractured level; $B$ is the diameter of the spinal canal at the superior nonfractured level; and $\mathrm{C}$ is the diameter of the spinal canal at the inferior nonfractured level [19].

All patients underwent X-ray, CT, and magnetic resonance imaging (MRI) examinations before PVP treatment. All patients met the following criteria: (1) single-segment OVBFs from T10 to L5; (2) spinal 
canal occupational ratio $\leq 20 \%$; (3) aged above 60 years and under 85 years; (4) no neurological dysfunction; (5) history of trauma $<7$ days; (6) low signal on T1-weighted and high signal on STIR sequences in the fractured vertebra and no evidence of posterior ligamentous complex injury according to MRI. Additionally, no patients had the following phenomena: (1) multiple-segment OVBFs; (2) pathology fractures; (3) long-term chronic low back pain; or (4) long-term use of hormone therapy or chemotherapy.

\section{Treatment Strategies}

All PVP treatments in all patients were performed by two surgeons. All procedures were performed by using intermittent $\mathrm{C}$-arm fluoroscopic guidance. The patients were placed in the prone position on the operating table. The hyperextension position of the lumbar vertebra achieved with an iliac and chest cushion placed under the body helped reduce the fractures. After local anesthesia, bilateral marks were made on the skin, and a small incision was made with a scalpel blade. All patients underwent the bilateral puncture approach to reduce the radiation dose. Two $10 \mathrm{G}$ bone-puncture needles $(03.702 .2185$, Vertecem V+, DepuySynthes, USA) were simultaneously placed transpedicularly in the fractured vertebra. On each side, the defined volume of high-viscosity $15 \%$ hydroxyapatite and the PMMA composite bone cement (07.702.016S, Vertecem V+, DepuySynthes, USA) was determined approximately $1.5-2.0 \mathrm{ml}$ at the T10-L5 segments. After puncturing the vertebral body, the outer cannula was retained, and the inner core was removed. Then, the lateral opening injection tool was inserted, and the bone cement flowed out only through the side opening, which helped control the injection direction (Figure 1A-B). The injection direction was as close as possible to the upper and lower endplates, and the bone cement was injected between the anterior $1 / 4$ and posterior $2 / 3$ of the vertebrae in the lateral view (Figure 1C-E). When cement had infiltrated into the anterior $1 / 4$ or posterior $1 / 4$ of the vertebrae according to the lateral view, the needle was repositioned for further injection, or the injection procedure was stopped. All patients were observed in the supine position for 4 hours after the PVP operation, and an overnight hospital stay was required. The patients were discharged the next day. All patients have been prescribed anti-osteoporosis treatment that included bisphosphonates and vitamin D analogues.

One day after PVP, X-ray and CT examinations were used to assess the bilateral longitudinal height of the bone cement in the treated vertebral body as well as cement leakage. According to Hou Y et al. [20], if the minimum distances of bone cement to the upper and lower endplates were simultaneously zero, "contacted" bone cement distribution was considered, and the other conditions were considered "uncontacted" bone cement distribution. If the bone cement "contacted" at least one side, the patients were recommended to undergo small amounts of physical activity with brace protection for 1 month. If the bone cement was "uncontacted" bilaterally, the patients were recommended to undergo absolute bed rest for three weeks. Regular extremity activities were encouraged in bed, such as active ankle movement; then, getting out of bed with brace protection was recommended. The time of increased activity was

determined by follow-up CT examinations, which showed callus formation. The operative levels, operative times, and amounts of injected bone cement were recorded in all patients. 


\section{Clinical And Radiological Assessments}

At least 12 months follow-up were performed. Preoperatively as well as 1 day, 1 month, 3 months, 6 months and last follow-up after PVP treatment, back pain was assessed with the Visual Analogue Scale (VAS). Fracture healing was examined by CT 1 month and 3 months postoperatively in all patients. In this study, if the fracture line in the posterior $1 / 4$ area of the vertebral body disappeared in CT images and two-dimensional reconstruction CT images, we considered it was healing of the fractured posterior wall. Anterior-posterior and lateral spinal radiograph examinations were examined 1 day, 1 month, 3 months and 6 months after PVP treatment, and the anterior, middle and posterior vertebral heights were measured from lateral radiographs for the treated vertebra and the adjacent nonfractured vertebrae. The vertebral height ratio was determined by dividing the height of the fractured (treated) vertebra by the mean height of the adjacent superior and inferior nonfractured vertebrae. Complications and adverse events were recorded in all patients during follow-up.

\section{Statistical Analysis}

SPSS19.0 (SPSS, Inc., Chicago, IL, USA) was used to analyze all data, and the results are expressed as the mean \pm SD. The VAS and vertebral height ratio data between the preoperative and postoperative follow-up time points were analyzed by paired-sample T-tests. Significance was set at $p<0.05$.

\section{Results}

\section{Demographic data and Surgical parameters}

Two patients were lost to follow-up, so the follow-up rate was $97.06 \%$ ( $66 / 68$ patients). Our study included 66 patients (mean age $72.10 \pm 7.98$ years, with 21 males and 45 females). The causes of the OVBFs included traffic accidents (16), high falls (18), low falls (22), and flat falls (10). The mean T-score was $-2.91 \pm 0.35$. The mean spinal canal occupational ratio was $12.64 \pm 3.28 \%$. There were T10-T11 (13), T12-L1 (36), and L2-L5 (17) fractures. The mean amount of bone cement was $3.28 \pm 0.35 \mathrm{ml}$ in the vertebrae. The mean operative time was $34.02 \pm 5.23 \mathrm{~min}$. 44 patients showed a "contacted" bone cement distribution bilaterally, 16 patients showed a "contacted" bone cement distribution unilaterally, and 6 patients showed "uncontacted" bone cement distribution bilaterally.

\section{Follow-up Outcomes}

The average follow-up duration was $21.23 \pm 9.35$ months after surgery. The results of the VAS scores are shown in Table 1. One day postoperatively, all patients showed obvious back pain relief $(P<0.05)$, and during the follow-up, VAS scores gradually declined. The radiological outcomes are shown in Table 2 . The mean anterior vertebral height ratio (AVHR), middle vertebral height ratio (MVHR) and posterior vertebral height ratio (PVHR) were significantly increased after PVP compared with preoperative values in all 
patients $(P<0.05)$. At the 6-month follow-up, the height ratio was not obviously decreased compared with early postoperative values. For the 60 patients with a "contacted" bone cement distribution on at least one side, continuous callus formation of the posterior wall of the treated vertebral body was found 1 month after the PVP operation. In addition, for the other 6 patients with "uncontacted" bone cement distribution bilaterally, there was no obvious fracture displacement or slight callus formation of the posterior wall on the CT images 1 month after PVP treatment. The fractures healed in all patients according to the 3-month follow-up CT images, and no patients experienced new burst fractures of the posterior wall in the treated vertebral body. Typical X-ray and CT images at different time points are shown in Figure 2. Cement leakage was observed in 7 patients, but none of these patients suffered from symptomatic leakage that caused neurological deficits, embolism, or death. Asymptomatic cement leakage included lateral venous (2), anterior fracture (2), lateral fracture (2), and disc (1) leakage. New adjacent vertebral fractures (2) and non-adjacent vertebral fractures (1) caused by flat falling occurred at 13 months, 15 months, and 16 months postoperatively, respectively. During bed rest, one patient had an infection of the urinary system. No patients had deep vein thrombosis, muscle atrophy, joint stiffness, hypostatic pneumonia, or decubitus.

Table 1

Changes in the VAS scores during follow-up

\begin{tabular}{|c|c|c|c|c|c|c|}
\hline & $\begin{array}{l}\text { Pre- } \\
\text { operation }\end{array}$ & $\begin{array}{l}\text { Postoperative } \\
1 \text { day }\end{array}$ & $\begin{array}{l}\text { Postoperative } \\
1 \text { month }\end{array}$ & $\begin{array}{l}\text { Postoperative } \\
3 \text { months }\end{array}$ & $\begin{array}{l}\text { Postoperative } \\
6 \text { months }\end{array}$ & $\begin{array}{l}\text { Last } \\
\text { follow-up }\end{array}$ \\
\hline VAS & $8.40 \pm 0.48$ & $3.78 \pm 0.42^{*}$ & $2.19 \pm 0.38^{*}$ & $1.60 \pm 0.38^{*}$ & $1.05 \pm 0.40^{\star}$ & $0.58 \pm 0.40^{*}$ \\
\hline \multicolumn{7}{|c|}{${ }^{*} \mathrm{p}<0.05$ vs pre-operation } \\
\hline \multicolumn{7}{|c|}{ Values $=$ Mean $\pm S D$} \\
\hline
\end{tabular}

Table 2

Changes in the vertebral height ratio during follow-up

\begin{tabular}{|llllll|}
\hline & $\begin{array}{l}\text { Pre- } \\
\text { operation } \\
(\%)\end{array}$ & $\begin{array}{l}\text { Postoperative } \\
\text { 1 day (\%) }\end{array}$ & $\begin{array}{l}\text { Postoperative 1 } \\
\text { month (\%) }\end{array}$ & $\begin{array}{l}\text { Postoperative 3 } \\
\text { months (\%) }\end{array}$ & $\begin{array}{l}\text { Postoperative 6 } \\
\text { months (\%) }\end{array}$ \\
\hline AVHR & $68.72 \pm 3.91$ & $85.36 \pm 3.08^{*}$ & $84.92 \pm 3.02^{*}$ & $84.20 \pm 2.98^{*}$ & $83.41 \pm 2.89^{*}$ \\
\hline MVHR & $81.32 \pm 3.27$ & $88.62 \pm 2.90^{*}$ & $88.46 \pm 2.85^{*}$ & $87.86 \pm 2.85^{*}$ & $87.41 \pm 2.86^{*}$ \\
\hline PVHR & $93.43 \pm 2.75$ & $94.67 \pm 2.47^{*}$ & $94.53 \pm 2.48^{*}$ & $94.18 \pm 2.44^{*}$ & $93.99 \pm 2.46^{*}$ \\
\hline $\begin{array}{l}\text { AVHT= Anterior vertebral height ratio; } \mathrm{MVHT}=\text { Middle vertebral height ratio; PVHT }=\text { Posterior vertebral } \\
\text { height ratio }\end{array}$ & & & \\
\hline
\end{tabular}




\section{Discussion}

For older patients suffering from vertebral body fractures with posterior wall disruption, called OVBFs, treatments are aimed to reduce back pain and promote healing of vertebral fractures, thus further avoiding fractured fragment displacement leading to nerve compression $[2-4,10]$. The mechanical stability of the fractured vertebral body is one of the most critical factors affecting the union of fracture $[21,22]$. Therefore, in this study, we attempted to inject bone cement as close as possible to the endplate using a lateral opening injecting tool; this procedure helped provide mechanical stability of the fractured vertebral body $[20,23,24]$. The bone cement was symmetrically and evenly distributed in the anteriormiddle part of the vertebral body, which increased the stability of the vertebra while reducing the risk of bone cement leakage into the spinal canal [25]. All patients achieved obvious back pain relief after treatment, most patients achieved early movement out of bed, and the bone fragments healed in all patients.

Some studies have attempted to use PVP or PKP to treat OVBFs and have obtained satisfactory results $[2-6,10,17,18]$. For example, Nakano et al. first performed PVP by using calcium phosphate cement to treat patients with thoracolumbar burst fractures without neurological deficits [18]. Then, Hiwatashi A and Westesson PL found OVBF patients with spinal canal compromise could be safely treated with PVP, and this treatment could reduce pain, decrease the wedge angle and increase the vertebral body height [6]. Furthermore, other authors reported that PKP was an effective and safe method for treating OVBF patients with spinal canal compromise, achieving obvious kyphotic angle reduction and vertebral height restoration and further leading to good pain relief and functional improvement $[3,4]$. However, all these reports did not specifically mention how to deal with the posterior wall of the fractured vertebral bodies and healing of the fractured posterior wall, which was a fundamental reason for the controversy on PVP or PKP to treat OVBFs. In this study, by adjusting the injecting direction through the lateral opening hole, the bone cement was kept away from the fractured posterior wall of the vertebral body and reduced the influence of blood supply of fractured areas as much as possible. We suggested that the union of the posterior vertebral wall in OVBFs could increase the stability of the fractured vertebral body, further reducing the risk of bone cement protrusion into the spinal canal and nerve compression due to bone cement loosening [7]. In addition, reoperations after PVP or PKP for removing bone cement displacement into the spinal canal are usually due to the incomplete union of the posterior wall of the vertebral body $[26,27]$. Therefore, in this study, we specifically observed the bone healing of the posterior wall of the fractured vertebral body. The distribution of bone cement in our patients was kept a certain distance from the fractured posterior fragments, which avoided the influence of bone cement on the blood supply of the bone fragments and provided the possibility of observing bone healing during imaging follow-up [28]. One month after the operation, the CT images showed callus formation at the posterior wall of the fractured vertebral body, which was an obvious sign of bone healing. Three months after the operation, the CT images showed that the bone fragments of the posterior fractured vertebral body had healed in all cases. In addition, the vertebral height of the fractured vertebral body was not obvious lost at 6 months postoperatively compared with 1 day, 1 month and 3 months postoperatively, and no patients complained of nerve dysfunction symptoms caused by bone cement loosening in the long-term follow-up. The above 
results proved that the posterior stability of the fractured vertebral body in OVBFs was important for longterm prognosis, and our surgical procedures might be helpful for the union of fractures in the posterior vertebral wall.

The distance between the PMMA bone cement and endplate is a crucial risk factor for the stability of the treated vertebrae after PVP or PKP, and the closer the distance of the bone cement is to the upper and lower endplates, the better the stability of the longitudinal support of the vertebral body [20,23, 24]. In addition, even the cement distribution in the fractured vertebral body might be the optimal pattern for providing better stability than bulky bone cement, and the symmetrical bilateral injection of bone cement may promote even cement distribution $[25,29]$. Because the posterior wall of the vertebral body was damaged in OVBF patients, many surgeons controlled bone cement only injection into the front 3/4 of the vertebra to reduce the risk of bone cement leakage into the spinal canal $[4,6]$. Therefore, when the patients got out of bed early, the vertical support provided by the bone cement in the anterior $3 / 4$ of the vertebral body was essential for loading the vertical pressure instead of the posterior wall of the fractured vertebral body to avoid the nonunion or displacement of bone fragments [8, 30]. Using the lateral opening bone cement injection tool, the direction of the lateral opening can be adjusted to artificially control the distribution of the bone cement as close as possible near the upper and lower endplates while reducing the appearance of bulky bone cement, making the bone cement distribution more even. In our study, $60 / 66$ cases demonstrated a "contacted" bone cement distribution on at least one side, and the bone cement distribution was symmetrical and even between the anterior $1 / 4$ and posterior $2 / 3$ of the vertebrae, which provides adequate mechanical support for the fractured vertebral body and is helpful for the healing of posterior bone fragments.

According to Denis' three-column system, the completed middle column structure, including the posterior wall of the vertebral body, the posterior longitudinal ligament and the posterior annulus fibrosus, is very important for maintaining the stability of the spine $[7,8]$. Although the bone cement could increase the stability of the anterior part of the vertebral body, we cannot confirm whether the whole vertebral body could fully bear the longitudinal pressure for the stability defect of the posterior $1 / 4$ of the vertebral body with a burst fracture. Some previous reports regarding PVP or PKP treatment for OVBFs did not pay special attention to the need for bed rest and did not propose related recommendations $[4,6,17]$. Once elderly patients suffer from poor healing of vertebral body fractures, such as refracture and Kummell disease, they usually need to undergo reoperations that require additional financial burden [29, 31]. Therefore, in this study, we recommended that patients perform some simple activities with lumbar brace protection for 1 month after the operation. In addition, previous studies have suggested that the distance between the bone cement and endplate could affect the stability of fractured vertebral bodies. Therefore, for the purpose of clinical safety, we recommend that 6 patients with "uncontacted" bone cement distribution stay in bed for 3 weeks to increase the stability of fractured vertebral bodies in the early stage. At the 3-month follow-up, the CT images showed that the fractures healed in all patients, and no patients experienced new burst fractures of the posterior wall in the treated vertebral body. Because the amount of time for bed rest was short, and moderate activities in bed were encouraged, complications 
due to bed rest were rare in our patients, except for one patient who suffered an infection of the urinary system.

There were some limitations in our study. First, the sample size was still small, which should be expanded in further studies. Second, for clinical safety, patients with "uncontacted" bone cement distribution were recommended to under absolute bed rest for 3 weeks in our study. However, there was no suggestion on whether bed rest protection was necessary and the length of bedtime for the patients with "uncontacted" cement distribution. Third, the patients with a different spinal canal occupational ratio who can be treated with our PVP method are not confirmed.

\section{Conclusions}

In summary, in the procedure of PVP, by using the lateral opening injection tool, the distribution of bone cement became controllable and safe, which help maintain vertebral body stability, and reduce the risk of spinal canal damage, further promoting fracture healing of the posterior wall of the vertebral body in asymptomatic OVBF patients.

\section{List Of Abbreviations}

PVP: Percutaneous vertebroplasty

OVBF: Osteoporotic vertebral burst fracture

VAS: Visual Analogue Scale

VH: Vertebral height

OVCF: Osteoporotic vertebral compression fracture

CT: computed tomography

\section{Declarations}

\section{Ethics approval and consent to participate}

The study protocol was approved by the ethics committee of our hospital (No.SH9H-2021-T258-2).

\section{Consent for publication}

Not applicable.

\section{Availability of data and materials}


The datasets used and/or analysed during the current study are available from the corresponding author on reasonable request.

\section{Competing interests}

The authors declare that they have no competing interests.

\section{Funding}

This work was supported by the National Natural Science Foundation of China (82071564), Fundamental research program funding of Ninth People's Hospital affiliated to Shanghai JiaoTong University School of Medicine (JYZZO70) and Natural Science Foundation of Shanghai (17ZR1416600, 19ZR1429200).

\section{Authors' contributions}

Wenjie Jin and Kangping Shen participated in the design of this study. Xin Sun, Jia Wang, Xingzhen Liu, Hairong Tao, Tong Zhu, Xiang Wang and Wenjie Jin carried out the study, collected background information, contributed to the clinical and radiological evaluations and wrote the manuscript. All authors read and approved the final manuscript.

\section{Acknowledgements}

None.

\section{References}

1. Zou J, Mei X, Gan M, Wang G, Lu J, Yang H: Is kyphoplasty reliable for osteoporotic vertebral compression fracture with vertebral wall deficiency? Injury 2010, 41(4):360-364.

2. Li CH, Chang MC, Liu CL, Chen TS: Osteoporotic burst fracture with spinal canal compromise treated with percutaneous vertebroplasty. Clinical neurology and neurosurgery 2010, 112(8):678-681.

3. Wang H, Zhang Z, Liu Y, Jiang W: Percutaneous kyphoplasty for the treatment of very severe osteoporotic vertebral compression fractures with spinal canal compromise. Journal of orthopaedic surgery and research 2018, 13(1):13.

4. Abdelgawaad AS, Ezzati A, Govindasamy R, Krajnovic B, Elnady B, Said GZ: Kyphoplasty for osteoporotic vertebral fractures with posterior wall injury. The spine journal: official journal of the North American Spine Society 2018, 18(7):1143-1148.

5. Chen JF, Lee ST: Percutaneous vertebroplasty for treatment of thoracolumbar spine bursting fracture. Surgical neurology 2004, 62(6):494-500; discussion 500.

6. Hiwatashi A, Westesson PL: Vertebroplasty for osteoporotic fractures with spinal canal compromise. AJNR American journal of neuroradiology 2007, 28(4):690-692.

7. Denis $F$ : The three column spine and its significance in the classification of acute thoracolumbar spinal injuries. Spine 1983, 8(8):817-831. 
8. Denis F: Spinal instability as defined by the three-column spine concept in acute spinal trauma. Clinical orthopaedics and related research 1984(189):65-76.

9. Goldstein CL, Chutkan NB, Choma TJ, Orr RD: Management of the Elderly With Vertebral Compression Fractures. Neurosurgery 2015, 77 Suppl 4:S33-45.

10. Zaryanov AV, Park DK, Khalil JG, Baker KC, Fischgrund JS: Cement augmentation in vertebral burst fractures. Neurosurgical focus 2014, 37(1):E5.

11. Nakano M, Kawaguchi $\mathrm{Y}$, Kimura T, Hirano N: Transpedicular vertebroplasty after intravertebral cavity formation versus conservative treatment for osteoporotic burst fractures. The spine journal: official journal of the North American Spine Society 2014, 14(1):39-48.

12. Lin HH, Chang MC, Wang ST, Liu CL, Chou PH: The fates of pedicle screws and functional outcomes in a geriatric population following polymethylmethacrylate augmentation fixation for the osteoporotic thoracolumbar and lumbar burst fractures with mean ninety five month follow-up. International orthopaedics 2018, 42(6):1313-1320.

13. Tomycz L, Parker SL, McGirt MJ: Minimally invasive transpsoas $L 2$ corpectomy and percutaneous pedicle screw fixation for osteoporotic burst fracture in the elderly: a technical report. Journal of spinal disorders \& techniques 2015, 28(2):53-60.

14. Bakhsheshian J, Dahdaleh NS, Fakurnejad S, Scheer JK, Smith ZA: Evidence-based management of traumatic thoracolumbar burst fractures: a systematic review of nonoperative management. Neurosurgical focus 2014, 37(1):E1.

15. Foulke BA, Kendal AR, Murray DW, Pandit H: Fracture healing in the elderly: A review. Maturitas 2016, 92:49-55.

16. Wang H, Sribastav SS, Ye F, Yang C, Wang J, Liu H, Zheng Z: Comparison of Percutaneous Vertebroplasty and Balloon Kyphoplasty for the Treatment of Single Level Vertebral Compression Fractures: A Meta-analysis of the Literature. Pain physician 2015, 18(3):209-222.

17. Ozsoy KM, Oktay K, Gezercan Y, Cetinalp NE, Okten Al, Erman T: Percutaneous Vertebroplasty for the Treatment of Osteoporotic Thoracolumbar Fractures with Posterior Body Involved in Elderly Patients. Turkish neurosurgery 2019, 29(1):90-94.

18. Nakano M, Hirano N, Matsuura K, Watanabe H, Kitagawa $H$, Ishihara H, Kawaguchi Y: Percutaneous transpedicular vertebroplasty with calcium phosphate cement in the treatment of osteoporotic vertebral compression and burst fractures. Journal of neurosurgery 2002, 97(3 Suppl):287-293.

19. Hayashi T, Maeda T, Ueta T, Shiba K, Iwamoto Y: Comparison of the amounts of canal encroachment between semisitting and supine position of computed tomography-myelography for vertebral fractures of the elderly involving the posterior vertebral wall. Spine 2012, 37(19):E1203-1208.

20. Hou Y, Yao Q, Zhang G, Ding L, Huang H: Polymethylmethacrylate distribution is associated with recompression after vertebroplasty or kyphoplasty for osteoporotic vertebral compression fractures: A retrospective study. PloS one 2018, 13(6):e0198407.

21. von Ruden C, Augat P: Failure of fracture fixation in osteoporotic bone. Injury 2016, 47 Suppl 2:S3s10. 
22. Phan K, Rao PJ, Mobbs RJ: Percutaneous versus open pedicle screw fixation for treatment of thoracolumbar fractures: Systematic review and meta-analysis of comparative studies. Clinical neurology and neurosurgery 2015, 135:85-92.

23. Kim YY, Rhyu KW: Recompression of vertebral body after balloon kyphoplasty for osteoporotic vertebral compression fracture. European spine journal: official publication of the European Spine Society, the European Spinal Deformity Society, and the European Section of the Cervical Spine Research Society 2010, 19(11):1907-1912.

24. Li D, Wu Y, Huang Y, Augustine B, Yue J: Risk factors of recompression of cemented vertebrae after kyphoplasty for osteoporotic vertebral compression fractures. International orthopaedics 2016, 40(6):1285-1290.

25. Liang D, Ye LQ, Jiang XB, Yang P, Zhou GQ, Yao ZS, Zhang SC, Yang ZD: Biomechanical effects of cement distribution in the fractured area on osteoporotic vertebral compression fractures: a threedimensional finite element analysis. The Journal of surgical research 2015, 195(1):246-256.

26. Wu CC, Lin MH, Yang SH, Chen PQ, Shih TT: Surgical removal of extravasated epidural and neuroforaminal polymethylmethacrylate after percutaneous vertebroplasty in the thoracic spine. European spine journal: official publication of the European Spine Society, the European Spinal Deformity Society, and the European Section of the Cervical Spine Research Society 2007, 16 Suppl 3:326-331.

27. Grelat M, Le Van T, Fahed E, Beaurain J, Madkouri R: Rare Complication of Percutaneous Technique: Intradural Cement Leakage and Its Surgical Treatment. World neurosurgery 2018, 118:97.

28. Hajnovic L, Sefranek V, Schutz L: Influence of blood supply on fracture healing of vertebral bodies. European journal of orthopaedic surgery \& traumatology: orthopedie traumatologie 2018, 28(3):373380.

29. Chen LH, Hsieh MK, Liao JC, Lai PL, Niu CC, Fu TS, Tsai TT, Chen WJ: Repeated percutaneous vertebroplasty for refracture of cemented vertebrae. Archives of orthopaedic and trauma surgery 2011, 131(7):927-933.

30. Haher TR, Felmy W, Baruch H, Devlin V, Welin D, O'Brien M, Ahmad J, Valenza J, Parish S: The contribution of the three columns of the spine to rotational stability. A biomechanical model. Spine 1989, 14(7):663-669.

31. Heo DH, Chin DK, Yoon YS, Kuh SU: Recollapse of previous vertebral compression fracture after percutaneous vertebroplasty. Osteoporosis international: a journal established as result of cooperation between the European Foundation for Osteoporosis and the National Osteoporosis Foundation of the USA 2009, 20(3):473-480.

\section{Figures}



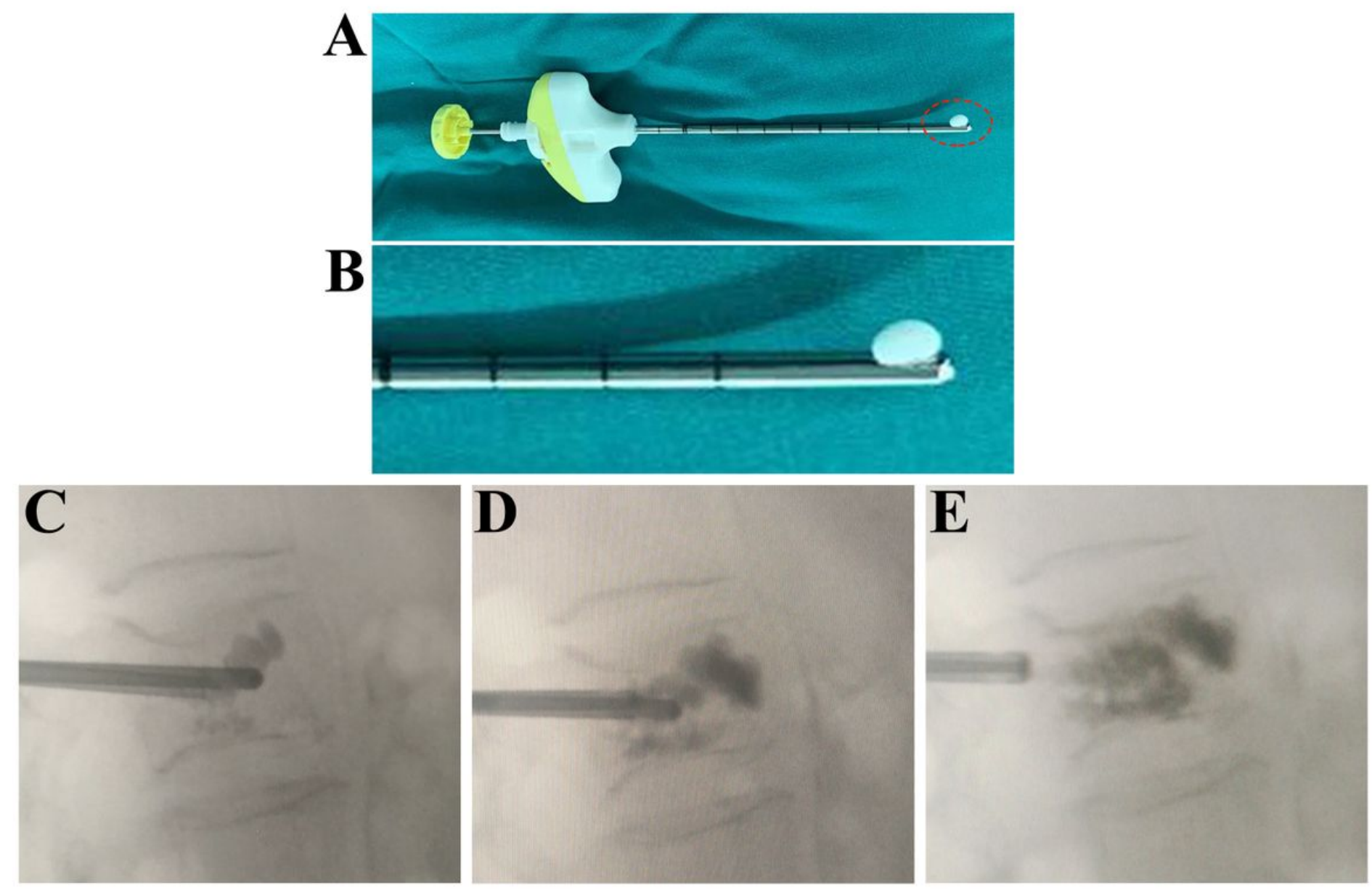

\section{Figure 1}

A-B: Images of the lateral opening injection tool used for PVP in our study; C-E: Intraoperative fluoroscopic images in the lateral view when injecting bone cement. The bone cement flowed out only through the side opening, which can help surgeons make bone cement contact the upper and lower endplates without a large amount of bone cement. 
A
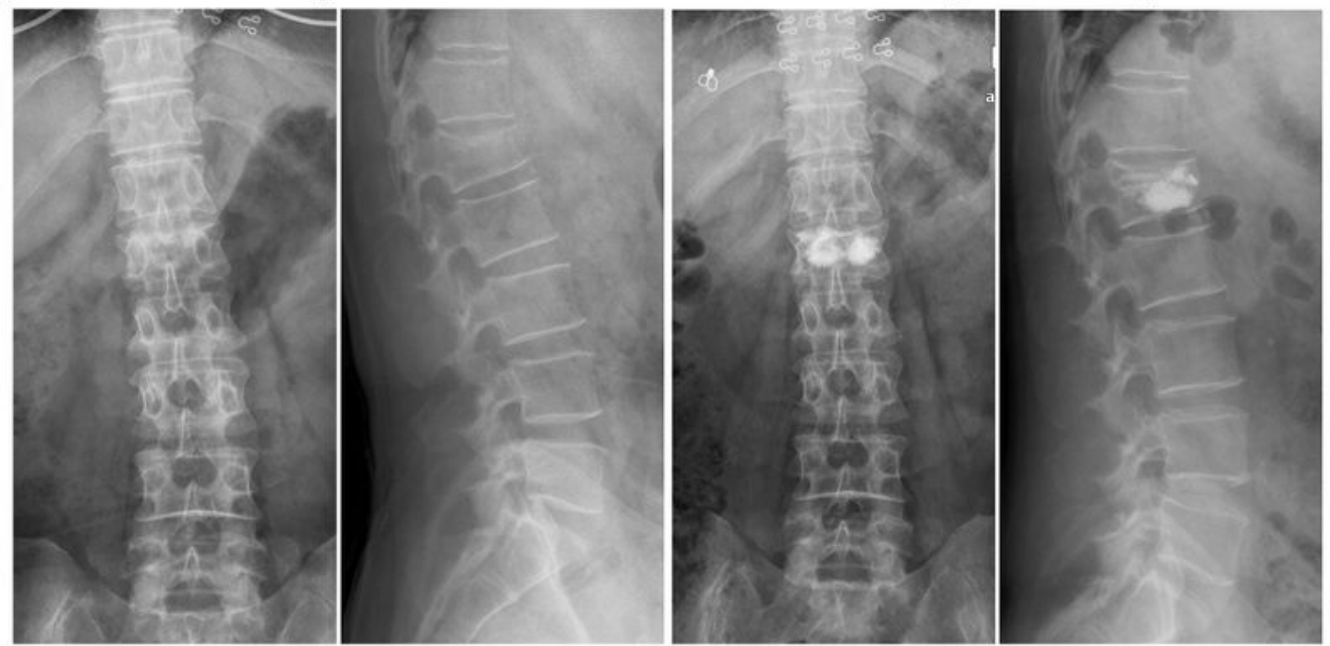

B Pre-opreation

Postopreative 1 day

Postopreative 1 month Postopreative 3 months
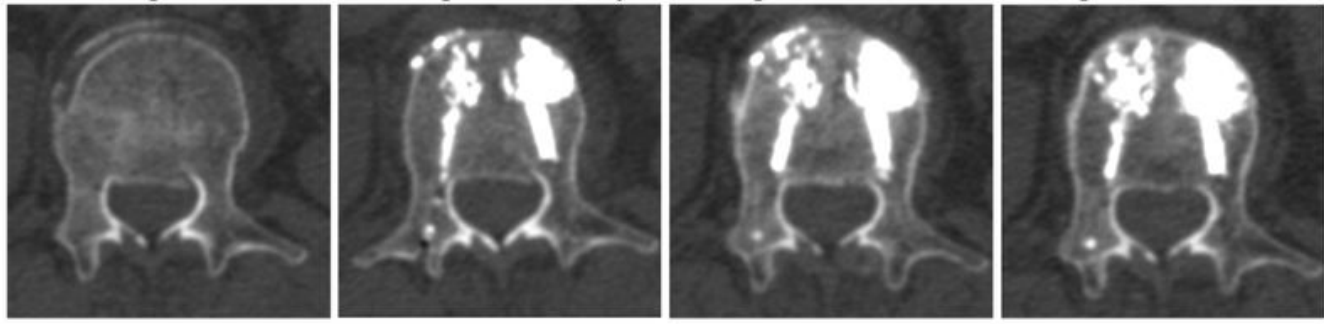

C
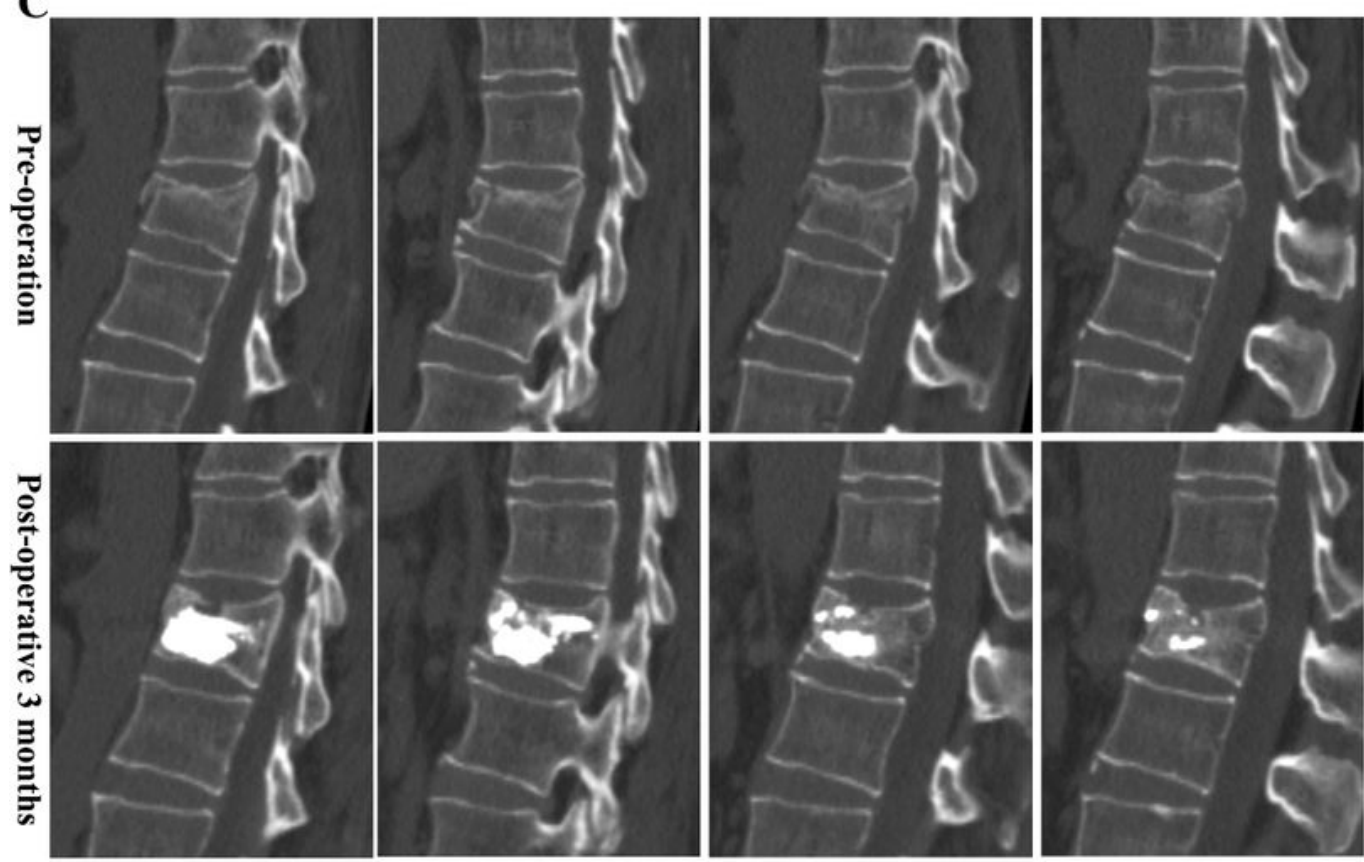

\section{Figure 2}

Typical case: a 68-year-old female with asymptomatic OVBF treated with our method. A: Anteriorposterior and lateral spinal X-rays preoperatively and 1 day postoperatively. There was a "contacted" bone cement distribution and obvious anterior and middle vertebral height ratio restoration after PVP; B: Transverse axial CT images at different time points. There was continuous callus formation of the posterior wall of the treated vertebral body 1 month postoperatively. The fracture healed at 3 months 
postoperatively. C: Corresponding sagittal reconstruction images of CT scans preoperatively and 3 months postoperatively. There was obvious bone healing of the posterior wall of the treated vertebrae. 